\title{
UM DIÁLOGO PLURICULTURAL SOBRE O ACESSO À SAÚDE COM MULHERES IMIGRANTES
}

A PLURICULTURAL DIALOGUE WITH IMMIGRANT WOMEN ABOUT HEALTH ACCESS

UN DIÁLOGO PLURICULTURAL CON MUJERES IMIGRANTES SOBRE EL ACCESO A LA SALUD

TEIXEIRA, Ivana dos Santos ${ }^{1}$

ROLLO, Rosane Machado²

ROCHA, Cristianne Maria Famer ${ }^{3}$

\section{RESUMO}

Os movimentos migratórios têm se caracterizado por uma crescente participação feminina que traz, por sua vez, desafios e complexidades relativos à inserção sociocultural, econômica e sanitária de mulheres nos países/locais para onde migram. Neste artigo, analisam-se as circunstâncias que levaram mulheres imigrantes a utilizar os serviços de saúde na cidade de Porto Alegre. Através de entrevistas semiestruturadas, foi possível compreender algumas das facilidades e das dificuldades vivenciadas por elas no cotidiano do acesso ao sistema de saúde.

Palavras-chave: Mulheres. Imigração. Sistemas de Saúde. Serviços de Saúde. Sistema Único de Saúde.

\section{ABSTRACT}

The migratory movements have been characterized by an increasing female participation that brings challenges and difficulties related to the socio-cultural, economic and health insertion of women in the countries/places they have migrated. In this article, we analyze the circumstances that led immigrant women to use health services in Porto Alegre, RS. Through semi-structured interviews, it was possible to understand some of the ease and the difficulties experienced by them in the daily access to the Brazilian health system.

Keywords: Women. Immigration. Health Systems. Health Services. Unified Health System.

\section{RESUMEN}

Los movimientos migratorios están caracterizándose por una creciente participación femenina que trae desafíos y complejidades relativos a la inserción sociocultural, económica y sanitaria de mujeres en los países/locales para donde migran. En este artículo, se analizan las circunstancias que llevaron a las mujeres inmigrantes a utilizar los servicios de salud en la ciudad de Porto Alegre en Brazil. A través de entrevistas semiestructuradas, fue posible comprender algunas de las facilidades y de las dificultades vivenciadas por ellas durante el acceso al sistema de salud.

Palabras clave: Mujeres. Inmigración. Sistemas de salud. Servicios de salud. Sistema Único de Salud.

\footnotetext{
${ }^{1}$ Universidade Federal do Rio Grande do Sul - UFRGS - Porto Alegre - Rio Grande do Sul - Brasil.

2 Universidade Federal do Rio Grande do Sul - UFRGS - Porto Alegre - Rio Grande do Sul - Brasil.

${ }^{3}$ Universidade Federal do Rio Grande do Sul - UFRGS - Porto Alegre - Rio Grande do Sul - Brasil.
} 


\section{INTRODUÇÃO}

Embora o Brasil esteja em constante adaptação aos movimentos migratórios, os equipamentos públicos e os profissionais que prestam serviços às populações imigrantes passam por diferentes desafios interculturais devido a sempre maior presença de populações advindas de países como o Senegal, Haiti e Venezuela. Na América do Sul, o Brasil foi o primeiro país a formular legislação nacional específica, tendo sido também um dos pioneiros na adesão ao regime internacional para os refugiados.

Na cidade de Porto Alegre, RS, a chegada mais recente de imigrantes iniciou após o terremoto ocorrido no Haiti, em 2010, e da crise econômica venezuelana, a partir de 2015. Sua inserção no espaço urbano, assim como de todo o território brasileiro, marca a constituição das cidades com uma base social dividida entre diferentes culturas. A maioria dos atuais imigrantes chegou na qualidade de refugiados, amparados pela lei do refúgio humanitário, e foram acolhidos na cidade através de convênios estabelecidos entre o Alto Comissariado das Nações Unidas para os Refugiados (ACNUR) e associações, secretarias municipais, universidades e outras instituições que prestam apoio e assistência a refugiados (BERNARDON, 2009).

Invisíveis para a maior parte da população local, os imigrantes têm muitas dificuldades no acesso a cuidados básicos de saúde e outros serviços, decorrentes das barreiras linguísticas e culturais que estão estreitamente associadas à falta de profissionais de saúde capacitados a entender as demandas diferenciadas que podem estar relacionadas à classe social, gênero, cultura, etc (SANTINHO, 2012; DIAS et al., 2011).

No caso das mulheres imigrantes, o atendimento e as técnicas de saúde empregadas deveriam considerar os diferentes grupos (questões sociais, políticas, culturais, econômicas, religiosas) e sua situação de vulnerabilidade, etnicidade, gênero, região de origem e destino. Além disso, outros diversos fatores expõem os sujeitos a um maior risco de acidentes de trabalho, abuso sexual, violência, abuso de drogas e transtornos psicológicos, assim como o risco de contrair doenças infecciosas como as Infecções Sexualmente Transmissíveis (IST), Vírus da Imunodeficiência Humana (VIH ou HIV, sigla em inglês), Síndrome da Imunodeficiência Humana Adquirida (SIDA ou AIDS, sigla em inglês), tuberculose e hepatites. Esses riscos são agravados pelo acesso limitado aos benefícios sociais e serviços de saúde dentro dos territórios de origem, trânsito, destino ou retorno.

Considerando-se que a experiência feminina nos processos de migração acaba por ser pouco abordada, tende-se a justificá-la pela menor porcentagem de mulheres nos dados oficialmente computados. Se algumas experiências de deslocamento eram prioritariamente masculinas, o contingente feminino cresceu gradativamente, podendo-se verificar um aumento no número de mulheres casadas, devido à ampliação das entradas em família e ações variadas de reconstituição familiar (LESSAULT \& FLAHAUX, 2013; DORNELAS e RIBEIRO, 2018; LIBERATO FILHO et al., 2019). Assim como outras categorias identitárias (AGIER, 2001), o gênero irrompe como um dos determinantes nos processos de migração e, embora mulheres e homens compartilhem desafios de saúde, as diferenças entre eles, tanto sociais quanto biológicas, faz da atenção à saúde das mulheres um tema que precisa ser mais bem estudado e compreendido no contexto das migrações. 
Nesse sentido, buscamos aqui analisar as circunstâncias que levaram mulheres imigrantes a utilizar os serviços de saúde na cidade de Porto Alegre, RS

\section{PERCURSO METODOLÓGICO}

Em nosso itinerário de pesquisa, tivemos acesso, inicialmente, a um grupo de venezuelanos, em processo migratório por refúgio, acolhido, na condição de abrigamento ${ }^{4}$, nas casas da Organização Não Governamental Aldeias Infantis SOS, localizada no Bairro Sarandi, zona norte da cidade de Porto Alegre ${ }^{5}$.

O segundo grupo de imigrantes que tivemos acesso foi acolhido na Vila Marista, um complexo de alojamentos localizado na região metropolitana de Porto Alegre. Sendo constituído, na sua maioria por famílias, as 39 pessoas vivenciaram o mesmo fluxo de entrada no Brasil que o grupo anteriormente citado: entraram no Brasil via Pacaraima, passaram pelo processo de acolhida e interiorização onde foram examinados e vacinados pela equipe de saúde ligada ao exército e, depois, destinados a diferentes regiões do Brasil para instalação final ${ }^{6}$.

Posteriormente, tivemos contato com um grupo de mulheres imigrantes que vivem na cidade de Porto Alegre há mais tempo e vieram para cá por diferentes motivos, mas principalmente para estudar.

De abordagem qualitativa e inspiração etnográfica, a pesquisa exploratório-descritiva foi realizada a partir de entrevistas semiestruturadas com imigrantes mulheres, moradoras da cidade de Porto Alegre, RS, usuárias de serviços de saúde. A modalidade de entrevista aberta ou não estruturada foi a escolhida, uma vez que permite às pesquisadoras trabalharem com um esquema de pensamento, "buscando sempre encontrar os fios relevantes para o aprofundamento da conversa" (MINAYO, 2008, p. 265). A ordem dos assuntos tratados não obedeceu a uma sequência rígida, pois essa é "determinada pelas próprias preocupações, relevâncias e ênfases que o entrevistado dá ao assunto em pauta" (MINAYO, 2008, p. 265).

As entrevistas foram realizadas em datas e locais previamente agendados com as participantes e seguiram um roteiro padrão e gravação de áudio, com autorização prévia, através da assinatura de Termo de Consentimento Livre e Esclarecido (TCLE) de acordo com a Resolução 466 do Conselho Nacional de Ética em Pesquisa (BRASIL, 2012). As entrevistas foram transcritas na íntegra e as gravações, assim como as transcrições, serão mantidas pelas pesquisadoras por cinco anos e, após

\footnotetext{
${ }^{4}$ Antes da adoção do visto para venezuelanos, em 2017, o Conselho Nacional de Imigração havia autorizado a residência temporária de dois anos a cidadãos de países limítrofes que estão fora do Acordo de Residência do Mercosul, o que beneficiava principalmente os venezuelanos. Eles passavam a ter o direito ao pedido de residência direta após vencido o seu visto de turista (noventa dias).

5 Parte de um grupo de 140 refugiados, que estavam alocados em Roraima, no norte do país, foram transferidos para quatro cidades gaúchas e, em Porto Alegre, ficaram 70 venezuelanos, todos abrigados em cinco casas da ONG Aldeias Infantis SOS. Eles chegaram na cidade em setembro de 2018 e passaram seis meses nesse local, tempo para encontrarem uma moradia fixa e emprego.

${ }^{6} \mathrm{O}$ Rio Grande do Sul foi o terceiro Estado a receber maior número de imigrantes venezuelanos. Através da Operação Acolhida, foram introduzidos, aqui, cerca de 900 venezuelanos, via processo de interiorização. O Estado de Roraima foi o que mais recebeu maior número de solicitações de refúgio em 2018: 63\% dos pedidos foram feitos lá, em seguida o Amazonas com 13\% e São Paulo com 12\%. O Rio grande do Sul recebeu apenas $2 \%$ das solicitações.
}

Reflexão e Ação [ISSN 1982-9949]. Santa Cruz do Sul, v. 29, n. 1, p. 84-97, jan./abr. 2021. https://online.unisc.br/seer/index.php/reflex/index 
transcorrido este tempo, as mesmas serão destruídas. $\mathrm{O}$ projeto $^{7}$ foi submetido e aprovado pelo Comitê de Ética em Pesquisa da Universidade Federal do Rio Grande do Sul (CEP/UFRGS), sob número 3.229.977, em acordo à Resolução 466/2012 (BRASIL, 2012).

Para a análise dos dados, foi realizada a análise de conteúdo (MINAYO, 2008), a partir do tema principal desta pesquisa, qual seja, a percepção, por parte das usuárias imigrantes, a respeito do acesso aos serviços de saúde a elas prestados/disponibilizados no Brasil.

\section{O ACESSO AOS SERVIÇOS DE SAÚDE POR MULHERES IMIGRANTES}

Ao observar as trajetórias de nossas interlocutoras, duas questões se destacam: aquela que fala das ações e tecnologias que partem do sistema de saúde convencional numa lógica de produção (vacinação, organização dos serviços) e aquela que depende da participação ativa do usuário e cujas ações evocam uma lógica processual. Essas questões, usadas como recurso analítico, nos permitem observar como se dá o acesso aos serviços de saúde, pelas mulheres imigrantes: de um lado, o sistema oferece ações e tecnologias para todos os usuários, independentemente de sua situação; e, de outro, em uma perspectiva pedagógica, as usuárias imigrantes reivindicam e ensinam sobre os cuidados que elas desejam/necessitam ter.

Em nosso campo de pesquisa, o acesso às tecnologias de saúde se dá formalmente ao/à migrante no momento da entrada no país ou, ainda antes, se o/a migrante observar algumas orientações/exigências para ingresso. Os sujeitos que entram no Brasil - tanto na condição de refugiado ou com visto para residência temporária - passam por uma avaliação médica onde há a presença de ações de imunização e controle sanitário. Posteriormente, o acesso aos serviços de saúde ocorre através das equipes que visitam os abrigos, no caso dos refugiados, ou por meio dos serviços disponibilizados pelo SUS.

Depois de passados os procedimentos de saúde iniciais, os migrantes passarão a acessar o SUS dentro das mesmas regras a que os brasileiros estão submetidos.

Ao buscar o Brasil como destino migratório, os sujeitos de qualquer nacionalidade, em tese, não são obrigados a comprovar vacinas ou profilaxia para entrada no país, contudo, o Ministério da Saúde recomenda que os turistas internacionais atualizem a sua situação vacinal previamente à chegada ao país, conforme as orientações do calendário do país de origem ou residência. O Ministério da Saúde (MS) e a Agência Nacional de Vigilância Sanitária (ANVISA) realizam a imunização e a triagem sanitária no contexto do êxodo venezuelano, em Pacaraima, em Roraima. Doenças como Difteria, Arbovírus e Sarampo tiveram incidência consideravelmente aumentada assim como os problemas advindos da ingestão de alimentos e água impróprios ao consumo, que se intensificaram. As ações desenvolvidas nesse processo de acolhida são: ações educativas, entrega de hipoclorito ${ }^{8}$,

\footnotetext{
7 Trata-se do Projeto de Pesquisa intitulado "Mulheres imigrantes na cidade de Porto Alegre: Um diálogo pluricultural sobre Saúde", que está sendo desenvolvido pela Dra. Ivana Teixeira, em estágio de pós-doutorado, sob a supervisão da Profa. Dra. Cristianne Maria Famer Rocha, junto à Universidade Federal do Rio Grande do Sul (UFRGS).

${ }^{8}$ A solução de hipoclorito de sódio, vulgarmente chamada "lixívia", é usada frequentemente como desinfetante e como agente branqueador.
} 
orientações acerca da importância da vacina e do certificado internacional, orientação a ambulantes vendedores de lanches. ${ }^{9}$

As entrevistadas, em nossa pesquisa, relatam que passaram por vacinação ao ingressarem no Brasil e aquelas que vieram com visto de estudos receberam as vacinas em seu país de origem. As mulheres venezuelanas, em particular, relatam que foram vacinadas inúmeras vezes e não sabiam dizer quais vacinas haviam sido administradas sobre seus corpos.

De modo geral, as vacinas que o Brasil recomenda à entrada de estrangeiros leva em consideração um calendário nacional do país de origem, justificado por razões socioambientais, ou seja, a procedência do visitante indica qual vacina ele deverá tomar antes de entrar no Brasil. Atualmente, as vacinas contra Sarampo, Rubéola, Febre Amarela e Difteria-Tétano-Poliomielite são altamente recomendadas e compõem o protocolo de atendimento em saúde a que os venezuelanos e demais imigrantes estão subjugados. Se o indivíduo vier de Angola ou da República Democrática do Congo, deve comprovar vacinação contra Sarampo com pelo menos dez dias de antecedência à entrada no país ${ }^{10}$. Na fronteira de Pacaraima, por exemplo, nos postos montados pela Força Tarefa do Exército, são oferecidos doze tipos vacinas, dentre elas: Hepatite B, Tríplice Viral e Dupla Adulto (Sarampo, Rubéola e Caxumba), Meningo C, Rotavírus, Penta, Influenza, entre outras, para crianças e adolescentes.

Percebe-se que a questão da vacinação pode variar muito de fronteira para fronteira, porque leva-se em consideração, para a oferta de determinada vacina, não somente os acordos internacionais de erradicação de algumas doenças (como Poliomielite) mas também os fatores locais como fauna, flora, clima, costumes e epidemiologia. O surto ${ }^{11}$ de Sarampo, por exemplo em Roraima e no Amazonas no ano de 2018, foi, por consenso científico, atribuído à crise na Venezuela, pois o tipo de vírus que foi encontrado nestes Estados era o mesmo que havia infestado a Venezuela no ano anterior (RODRIGUES et al., 2018). Além da alta transmissibilidade do vírus e do movimento migratório responsável por trazê-lo Brasil, afirma-se que a baixa taxa de vacinação (o Ministério da Saúde não tem alcançado o objetivo de vacinar $85 \%$ da população) no Brasil contribuiu para a proliferação da doença (RODRIGUES et al., 2018).

Depois das ações de imunização, o estrangeiro, portando seu cartão SUS, quando necessitar de um atendimento em saúde, deve buscar os diferentes serviços. Esse procedimento demanda uma série de habilidades da parte do imigrante e as entrevistas nos permitem ver algumas implicações disso na vida cotidiana das mulheres. Nossas interlocutoras explicitaram que a escolha pelos serviços de saúde recaiu nas unidades de saúde próximas à residência e/ou um serviço indicado por outra pessoa. Todavia, o acesso a estes serviços nem sempre foi facilmente compreendido por algumas

10 Informações disponíveis em: http://www.saude.gov.br/component/content/article/1335-saude-doviajante/9643-preparativos-para-a-viagem\#estrangeiros

${ }^{11} \mathrm{Em}$ Roraima, tivemos 200 casos confirmados e 177 sob investigação; no Amazonas, 263 casos confirmados e 1.368 sob investigação; além de seis casos confirmados no Rio Grande do Sul. No Rio de Janeiro, havia uma suspeita e, em São Paulo, a Secretaria de Saúde editara um alerta em nível 3, o mais alto da escala, para o risco de surto da doença (TARDÁGUILA e MARÉS, 2018). 
entrevistadas. A necessidade de se ter/fazer o Cartão SUS, por exemplo, não era de conhecimento de todas as entrevistadas que referiram sentir falta de maiores informações acerca da sua confecção, como podemos ver a partir do excerto da fala de uma participante, médica moçambicana, de 33 anos e residente há 5 meses no Brasil, cuja vinda se deu para fazer um curso de pós-graduação:

\begin{abstract}
Eu pessoalmente nunca perguntei e por acaso ninguém nunca me falou sobre isso [como se cadastrar no SUS]. Eu descobri há pouco tempo que existia um cartão do SUS, pelos meus colegas, residentes que têm o cartão do SUS, e eu olhei e pensei "ah tem um cartão, como é que eu faço para conseguir esse cartão? (...) se tu quiseres ir para o hospital vai ter que ter o cartão? Se for aqui no hospital (...) tens que pagar, ou terias que ter um convênio, ou terias que pagar sozinha pela medicação, pelo atendimento?". Então é uma coisa que ninguém explica e como eu estou lá acabei entendendo um pouquinho como funciona, que tem o paciente do SUS (...). Creio que tem que ter mais informação porque é uma experiência, a pessoa não está no seu país, tem um sistema diferente, tem cultura diferente, então, eu acho que é bastante importante. (Participante 1)
\end{abstract}

Além disso, o acesso ao SUS é organizado a partir da territorialização e da adscrição que leva os serviços/trabalhadores a negarem atendimento para as pessoas que não sejam moradoras da região em que determinada unidade de saúde se encontra. A adscrição, um dos princípios organizativos do SUS, acaba por dificultar o acesso daquelas pessoas que residem longe do trabalho ou do local do estudo, por exemplo. Um exemplo desta dificuldade foi relatado pela comunidade venezuelana, que ficou hospedada em uma região periférica da cidade de Porto Alegre. Eles chegaram exaustos da longa viagem que os trouxe do outro extremo do país, as crianças estavam com baixo peso e alguns problemas de saúde urgentes foram aparecendo. Embora existisse uma grande articulação interinstitucional no acolhimento dos grupos, a localização dos serviços de saúde impedia que certas intercorrências fossem resolvidas de maneira mais rápida.

Casos de urgência odontológica, pneumonia, pressão alta (hipertensão) e febre alta (decorrente de gripe em uma criança) transformaram-se em situações de muito sofrimento por parte dos venezuelanos, porque ninguém sabia a qual unidade de saúde deveriam encaminhá-los. Por um lado, havia o acolhimento aos refugiados, por parte das associações de ajuda humanitária, mas os serviços de saúde não haviam sido contatados e conectados ao processo de acolhimento. Assim, mesmo que, desde o ingresso no Brasil, os refugiados venezuelanos já tivessem sido identificados/cadastrados, por não terem recebido informações relativas ao Cartão SUS e a qual unidade de saúde deveriam se reportar, eles não sabiam como resolver seus problemas de saúde, sobretudo os mais urgentes.

Somado a essa realidade, foi referido também por uma entrevistada que o sistema de marcação de consultas de algumas unidades de saúde pode igualmente dificultar o acesso, uma vez que exige do usuário um esforço extraordinário para acessar o sistema e manter-se em tratamento contínuo. No excerto abaixo, uma entrevistada, psicóloga, moçambicana, de 30 anos, explica como os horários para o atendimento não eram compatíveis com sua rotina de trabalho, o que inviabilizou o acesso aos serviços de saúde: 
Então, quem é autônomo não tem para quem se justificar, né? (...) E teve uma outra vez que eu estava com um terçol, meu olho estava desse tamanho e estava doendo muito. Eu não sabia o que era, daí eu fui na farmácia e eles falaram: tu tens que ir no pronto socorro. Eu fui, eles me fizeram algumas perguntinhas e uma médica veio me avaliar bem rapidinho e ela me falou que eu tinha que ir lá não sei aonde, nem sei que bairro era, no pronto socorro dos olhos e eu fiquei assim (...) E aí eu fui até lá, tive que tirar o dia inteiro quase, eu cheguei cedo e fiquei até de tarde. E quando eu cheguei no consultório, foi cinco minutos, para ela me falar que eu estava com um super terçol... podia ter passado no corredor e ter falado: Ah! isso aqui é rápido é só olhar e falar que é um terçol. (Participante 2)

Tal depoimento parece evidenciar que a saúde de pessoas em situação de migração, antes de mostrar alguma determinação biológica ou cultural para o desenvolvimento de doenças, é agravada pelo acesso limitado aos benefícios sociais e serviços de saúde dentro dos territórios de origem, trânsito e destino (FASSIN, 2000).

Quando questionadas sobre o uso dos serviços de saúde, as participantes mencionaram que recorrem aos serviços privados, sobretudo para consultas de especialidades médicas, onde os serviços públicos são demorados, obrigando o usuário a aguardar meses por uma consulta, o que corrobora com os dados encontrados em outras pesquisas em diferentes contextos (TOPA et al., 2013; DIAS et al., 2009). Quando questionadas sobre a acessibilidade a tecnologias disponíveis no sistema público de saúde, a totalidade das interlocutoras manifestou a supremacia dos serviços brasileiros em relação ao seu país de origem. Contudo, o acesso a essas tecnologias é, mais uma vez, dificultado pelo modo como o sistema se organiza, tal como nos conta a também moçambicana de 30 anos de idade, psicóloga, que chegou ao Brasil há 1 ano e 6 meses. Seu relato, ainda que longo, é exemplar a respeito dos problemas de acesso até agora elencados:

\begin{abstract}
(...) eu já consultei com um ginecologista porque eu tive um problema de saúde (...), consultei e fiz os exames todos. Fiquei na lista de espera, porque eu tinha que fazer ecografia, só que quando chegou o dia da ecografia, eles ligaram para o meu marido, eu não sei o que que houve, mas a linha não estava boa, ele não ouviu direito (...). quando eu fui lá, no dia seguinte, eu expliquei que ligaram para ele e que ele não entendeu que era por causa do exame. Só que a moça disse que já não era possível, pois como não conseguiu falar, o exame tinha sido cancelado. Então eu estou de novo na fila, agora para fazer aqui, no Santa Marta (...) fiquei um pouquinho triste quando eu fui lá, no dia seguinte, cedo pra tentar entender e a moça disse: "não, está cancelado!". Levando em conta que eu fiquei mais de um ano esperando para ser atendida e, de uma hora pra outra, foi cancelado. Eu acho que poderia existir pelo menos um dia de espera para ver se a pessoa tem mesmo interesse. Ligaram num dia de tarde e eu fui no outro dia de manhã... então eu acho que poderiam esperar até o meio dia do dia seguinte para ver se eu iria para depois cancelar (...) eu acho que faltou um pouquinho de empatia, mas eu não quero me vitimizar, eu não quero pensar que elas fizeram isso porque eu não sou daqui, porque eu sou estrangeira... eu não quero pensar, mas eu acho que faltou um pouquinho de empatia. (Participante 3)
\end{abstract}

Para aquelas ações que necessitam da participação ativa do usuário, como a confecção do cartão SUS, a marcação/presença em consultas e exames, é visível o desajuste entre aquilo que é esperado pelo sistema e aquilo que o usuário consegue executar. As barreiras na promoção à saúde e no cuidado aos imigrantes, do ponto de vista dos trabalhadores, exigem uma atenção maior ao indivíduo que muda frequentemente de residência, não possui recursos econômicos suficientes para manter, por exemplo, uma linha telefônica, tem crenças e tradições religiosas, culturais e linguísticas diferentes, tem medo de denúncia quando se encontra em situação irregular e desconhece como ter acesso aos serviços de saúde (DIAS et al., 2011). Isso nos mostra que seja do ponto de vista das 
usuárias ou dos profissionais, a saúde das populações não é unicamente uma consequência das intervenções sanitárias, mas é também uma ação que deve estar amparada em uma compreensão maios do contexto sócio-político e cultural, que deve sim levar em conta as dinâmicas das representações tradicionais, as concepções populares sobre a doença, o sistema biomédico e as práticas e tecnologias em jogo (BLANC \& MONNAIS, 2007).

Alguns itinerários terapêuticos são muito semelhantes entre imigrantes e população do país receptor. As mulheres venezuelanas, por exemplo, quando comparam o sistema sanitário de seu país de origem com o SUS, afirmam que aqui o sistema de saúde é melhor: "lá na Venezuela antes era assim, mas agora não tem mais nada, nem remédio, nem exames” (participante 4). Esta participante aponta, ainda, as diferenças entre o sistema de saúde público e o sistema privado, pois, no Brasil, o setor privado é inacessível economicamente, sobretudo, em relação às consultas e procedimentos com especialistas: "aqui é mais medicalizado, é mais clínico porque os médicos pedem muitos exames e quando tu não consegues pelo sistema público, o particular é muito caro, bem mais caro que lá" (participante 4). Por outro lado, esta participante indicou como algo positivo e inédito o fato de que as enfermeiras podem receitar alguns tratamentos ou avaliar alguns exames, agilizando o atendimento, uma vez que, na Venezuela somente os médicos têm essa autoridade.

Contudo, para diferentes participantes, foi a questão da empatia que apareceu como elemento crucial para o cuidado em saúde. Sobretudo para aqueles itinerários terapêuticos que demandam um acompanhamento prolongado e podem ser interrompidos, ter seu efeito alterado ou até mesmo fracassar como processo se a relação usuária-trabalhador(a) não for suficientemente forte e empática. Em algumas entrevistas, fica evidente o desajuste entre o requerido/desejado às mulheres imigrantes e o possível de ser realizado, em função das dificuldades que enfrentam e que nem sempre são bem compreendidas pelos trabalhadores e gestores dos serviços de saúde.

Outro fator que leva as imigrantes a uma menor aderência aos projetos terapêuticos propostos está relacionado à variação de profissionais durante o processo. Uma participante, psicóloga, natural de Guiné Bissau, residente no Brasil há mais de 10 anos, casada, mãe de um menino de 3 anos, fez todo o seu pré-natal em uma unidade básica de saúde e teve o parto em um hospital público. A experiência de ter vivido a gravidez, as práticas em torno do pré-natal e as intervenções relativas ao parto, na condição de uma mulher imigrante, demonstram como estas situações, geralmente corriqueiras para as mulheres brasileiras, podem ser bastante traumáticas e difíceis para elas:

(...) eu cheguei lá com pouca dilatação, às $5 \mathrm{~h}$ da tarde. Estourou minha bolsa e eu fui para o hospital. Como eu sou um pouco medrosa, no início, queriam me tirar sangue e eu não aceitava (..) eu cheguei e comecei a ter contrações, mas não tinha dilatação para dar à luz. Por causa das contrações, eu comecei a gritar, meu marido estava junto, e eles só controlavam o bebê, a dilatação e a respiração. (...) cada vez que eles vinham ver como estava, só tinha dois de dilatação, não avançava. O medo continuava, mas eles não me deram anestesia, não deram aquele medicamento que induz o parto e eu não sei por que eles não fizeram isto, se foi porque eu chorava muito, se eles achavam que eu poderia não aguentar... Então eu fiquei lá até às $4 \mathrm{~h}$ da madrugada. Até que chegou o momento que eles perceberam que a criança estava sofrendo, estava com menos batimentos e disseram: vamos fazer uma cesariana de emergência. (Participante 5) 
A participante também relatou o fato de que seu pré-natal não foi feito por um único médico, durante o período da gestação e que, se tivesse sido feito, isto facilitaria ou permitiria a criação de vínculo entre a usuária e o profissional. Para ela, o fato de não suportar a dor (ter chorado, ter ficado muito nervosa) poderá estar ligado à falta deste vínculo e, também, à forma como os profissionais "naturalizaram" o fato de ela sentir dor, talvez por ela ser estrangeira:

\begin{abstract}
Poderia ter sido bom o acompanhamento com um único profissional ao longo do pré natal. Até para poder se criar um vínculo. E a questão do incentivo ao parto normal e os relatos das experiências de algumas mulheres que eu conheço... porque muitas mulheres têm essa dificuldade de ter uma dilatação rápida (...). Agora, eu tenho muito medo de ter outro filho por causa disso. Eu fico pensando que eu vou ter outro filho só quando eu tiver condições de já marcar a cesariana. Não quero mais sofrer de novo desse jeito. Mas teve gente que me contou que tiveram sorte e não sentiram tanta dor, pois deram anestesia e foi menos sofrido. Não tiveram dilatação, mas também não sentiram dor. (Participante 5)
\end{abstract}

O sentimento de incompreensão também pode ser percebido na história de outra participante, venezuelana, que imigrou com a família (marido e filho) para o Brasil e, estando grávida, pariu seu segundo filho na cidade de Boa Vista, em Roraima. O relato sobre o parto normal de seu segundo filho é testemunho de uma experiência traumática. Ela conta que, ao chegar na unidade de saúde, os profissionais riam por ela não entender português; no hospital, ela e o marido sentiram-se isolados e abandonados enquanto ela urrava de dor pelos corredores, pedia por uma cesariana, mas os profissionais não conversavam, pediam que ela se acalmasse, mas não a "explicavam" satisfatoriamente o porquê de tanta dor. Ao final de doze horas de contrações, esta mulher teve seu segundo filho por parto normal, algo que ela não desejava e que foi muito sofrido: "se eu tivesse tido meu primeiro filho de parto normal, certamente eu não teria coragem de ter um segundo" (participante 6).

As situações relatadas mostram que a falta de empatia no acolhimento implicou negativamente no sentimento produzido nas mulheres, em momentos importantes de suas condições de saúde. A relação estabelecida entre usuárias e profissionais, no cotidiano dos serviços de saúde, evidencia que o sentido e a prática do acolhimento são abrangentes e perpassam os mais variados campos e processos de saúde e implicam, ainda, a produção de subjetividades, de acordo com as experiências vividas e as práticas de saúde utilizadas. A subjetividade pode ser entendida como um "conjunto de modos de percepção, afeto, pensamento, desejo, medo e assim por diante, que animam os sujeitos atuantes" (ORTNER, 2007, p.:376)

De acordo com as entrevistas realizadas, a gratuidade do sistema e o acesso universal são as principais características do SUS que o diferencia de outros sistemas nacionais de saúde, assim como, a infraestrutura - quanto ao número de profissionais, as tecnologias disponíveis e as instalações das unidades de saúde: "uma das coisas que eu acho positivo é a gratuidade do serviço, não ter que pagar para ser atendido" (participante 4).

Dentre as participantes, uma delas - colombiana, enfermeira, professora universitária, casada, mãe de um menino e que mora no Brasil há dois anos - relata que sua primeira experiência no sistema de saúde foi levar o filho a uma unidade de saúde, onde foi bem atendida. Ao ser questionada sobre o que considera mais importante em relação ao acesso aos serviços de saúde no Brasil, indica: 
Primeiro, a cobertura, porque nós, mesmo sendo estrangeiros, temos coisas aqui que em nosso país não temos... lá, nós temos um plano de saúde, mas quando você precisa procurar um serviço, a instituição que presta o serviço tem que ligar para o seu administrador e pedir autorização para ter o atendimento. Então, aqui, não ter essa barreira, eu achei ótimo. [Também gostei] que é aberto para todos e achei os serviços bons. (Participante 6)

Essa opinião é compartilhada por outra usuária, originária da República do Congo, que chegou em Porto Alegre em fevereiro de 2017 e é estudante de graduação em uma universidade pública. Ela relata que teve inúmeras experiências com o sistema de saúde e que seu primeiro contato foi em Curitiba, quando ainda não falava Português. Com a ajuda de amigos, que explicaram como acessar o SUS, conseguiu seu primeiro atendimento. Depois, em Porto Alegre e com o passar do tempo, conseguiu se habituar aos serviços e a língua deixou de ser uma barreira:

\begin{abstract}
Lá no meu país, público ou privado tem um valor para pagar. Acho que os profissionais do meu país não têm muita empatia, eles são muito técnicos. Até demais! Ele chega e pergunta: "o que tu tens?" E... pronto, acabou! Aqui eles têm um pouco de empatia, conversam um pouco mais com o paciente do que lá. Lá eles são muito técnicos, querem o dinheiro e acabou. Eles não têm aquele tempo de querer saber um pouco mais sobre o paciente. (Participante 7)
\end{abstract}

Outra imigrante, originária de Moçambique, com 27 anos de idade, psicóloga, estudante e há 3 anos vivendo no Brasil, disse que a maior diferença entre o Brasil e o seu país de origem foi a alimentação. E foi justamente por este motivo que teve que recorrer a um serviço de saúde, logo que chegou, por problemas gástricos. Também ela relata que sua experiência foi positiva e ressalta a qualidade do acolhimento:

Eu acho que o Brasil tem uma coisa que é muito legal, que é a sensibilidade no atendimento ao público. Eu sei que tem problemas, eu sei que tem falhas, mas é um impacto grande de quem vem de Moçambique para cá. (...) Certamente, o atendimento é muito atencioso, é detalhado, é sensível, tem um acolhimento simpático, com empatia. E isso foi o que me causou maior impacto. (Participante 8)

Embora os serviços do SUS tenham particularidades historicamente construídas, como o sistema de marcação de consultas, por exemplo, as ações que compõem os atendimentos/protocolos utilizam marcadores sociais (como a cultura local ou as doenças que podem ser "trazidas" com os migrantes) e tecnologias que visam controlar o desenvolvimento de algumas doenças em detrimento de outras (controle infeccioso de doenças como Malária, Dengue, Zika, DSTs, Tuberculose, doenças mentais, entre outras) para identificar as necessidades dos usuários. Contudo, é consenso que migrantes apresentam perfis distintos no que se refere à autoavaliação e percepção do estado de saúde, às representações, crenças e atitudes face à saúde e à doença, às experiências e comportamentos, aos estilos de vida e às práticas de saúde e percursos de doença (DIAS et al., 2009; ROCHA et alii, 2012).

Como nos lembra Didier Fassin (2000), tradicionalmente, o migrante é considerado um risco e requer cuidados especiais, devido à sua suposta diferença, "em grande parte construída pelas 
instituições" (p.5). A saúde dos imigrantes não existe em si mesma, incorporada em genes, micróbios ou processos psíquicos, mas existe no relacionamento que historicamente foi construído pelos atores sociais (FASSIN, 2000). No contexto da França, por exemplo, os problemas e as doenças enfrentadas por pessoas em situação de imigração são de naturezas diferenciadas, sobretudo relativas ao acesso, ao cuidado ou à qualidade do cuidado oferecido, que tem mais a ver com a falta de conhecimento dos direitos ou de uma espécie de má vontade dos agentes de saúde (FASSIN, 2000). Essa questão foi trazida também por Santinho (2012), a respeito da realidade vivida por caboverdianos em Lisboa, como uma certa resistência (que ela chamou de "incompetência cultural") existente entre os profissionais de saúde em reconhecer a inadequação e os limites das suas práticas e modelos interpretativos quando encontram diante de si, no contexto de um atendimento, pessoas em sofrimento com outros códigos culturais e linguísticos.

\section{CONSIDERAÇÕES FINAIS}

O acesso aos serviços de saúde, seja para populações nacionais quanto para as populações migrantes, tem representado um desafio sempre mais complexo, sobretudo em decorrência das limitações econômicas impostas aos sistemas de proteção social, em todas as partes do mundo, nos últimos anos.

Ainda que o Brasil esteja sendo diretamente afetado pelas atuais decisões políticas contrárias à manutenção dos direitos adquiridos, no passado recente, em linhas gerais, as mulheres imigrantes, por nós entrevistadas, relatam satisfação com a oferta de serviços de saúde disponibilizadas a elas, no Brasil e, sobretudo, com o fato de tais serviços (ainda) serem gratuitos. Por outro lado, algumas referem situações vividas bastante desconfortáveis e traumáticas, em particular aquelas relacionadas à experiência do parto.

Destacamos também que praticamente todas indicam dificuldades em compreender como acessar os serviços de saúde (como fazer o Cartão SUS, qual a sua unidade de adscrição, quais são os serviços de emergência, entre outras demandas), mas depois que os acessam, dizem se sentir satisfeitas com os serviços oferecidos. Algumas ficam até surpresas com o fato de os brasileiros "não valorizarem o que tem". Por outro lado, também referem a inacessibilidade aos serviços privados de saúde, em função dos valores cobrados.

Comparativamente, embora não tenha sido o objetivo desse trabalho, foi interessante observar as diferenças relatadas por elas entre os sistemas de saúde dos países de onde vieram (Venezuela, Moçambique, Guiné Bissau, Colômbia, República do Congo) e aqueles do Brasil, em relação ao acesso, à cobertura, ao financiamento, à organização da atenção à saúde, dentre outras. Talvez tais diferenças e semelhanças devessem ser mais bem estudadas, no futuro, a fim de que seja possível produzir conhecimentos úteis para superaremos situações difíceis semelhantes e aprendermos, uns com os outros, a partir das boas experiências empreendidas aqui e em outros lugares.

Por fim, espera-se que estudos como este permitam compreender como se dá a experiência de acesso a serviços de saúde pelas populações imigrantes (em particular, pelas mulheres) e quais as 
práticas e as políticas que deveriam ser criadas, fortalecidas ou evitadas para gerar mais equidade entre populações tão diferentes entre si.

\section{REFERÊNCIAS}

1. AGIER, Michel. Distúrbios identitários em tempos de globalização. Mana, Rio de Janeiro, v. 7, n. 2, p. 7-33, Out. 2001. Disponível em: <https://doi.org/10.1590/S0104-93132001000200001>. Acesso em 7 Dez. 2019.

2. BERNARDON, A.C. População refugiada reassentada no Rio Grande do Sul: histórias de saudades e resistência. Porto Alegre: PUCRS, 2009. Dissertação (Mestrado em Serviço Social). Programa de Pós-Graduação em Serviço Social, Escola de Humanidades, Pontifícia Universidade Católica do Rio Grande do Sul, 2009. Disponível em: <http://tede2.pucrs.br/tede2/handle/tede/442>. Acesso em: 15 nov. 2019.

3. BLANC, M. e MONNAIS, L. Culture, immigration et santé: La consommation de médicaments chez les Vietnamiens de Montréal. Revue européenne des migrations internationales, v. 23, n.3, p. 151176, 2007. Disponível em: <https://doi.org/10.4000/remi.4238>. Acesso em: 10 nov. 2019.

4. BRASIL. Ministério da Saúde. Resolução 466: Diretrizes e normas regulamentadoras de pesquisa envolvendo seres humanos. Diário Oficial da República Federativa do Brasil, Brasília, 2012. Disponível em: <https://bvsms.saude.gov.br/bvs/saudelegis/cns/2013/res0466_12_12_2012.html>. Acesso em: 10 nov. 2019.

5. DIAS, S.; GAMA, A.; SILVA, A. C.; CARGALEIRO, H.; MARTINS, M. Acessibilidade à saúde pelos imigrantes em Portugal. Acta Medica Portuguesa, Lisboa, n.24, v.4, p. 511-516, 2011. Disponível em: $\quad$ <https://www.actamedicaportuguesa.com/revista/index.php/amp/article/download/492/200>. Acesso em: 30 nov. 2019.

6. DIAS, S. M. F.; ROCHA, C. F. e HORTA, R. Saúde sexual e reprodutiva de mulheres imigrantes africanas e brasileiras: um estudo qualitativo. Lisboa: Paulinas, 2009. Disponível em: <https://www.om.acm.gov.pt/documents/58428/177157/OI_32.pdf/059d23a1-370f-49a3-a2ab70077b24d69d>. Acesso em: 30 nov. 2019.

7. DORNELAS, P. D. e RIBEIRO, R. G. N. Mulheres Migrantes: invisibilidade, direito à nacionalidade e a interseccionalidade nas políticas públicas. O Social em Questão, n. 41, p.3, Maio/Ago., 2018. Disponível em: $<$ http://osocialemquestao.ser.pucrio.br/media/OSQ_41_art_11_Dornelas_Ribeiro.pdf>. Acesso em: 17 dez. 2019. 
8. FASSIN, D. Repenser les enjeux de santé autour de l'immigration. H\&M: Santé, le traitement de la différence, n. 1225, Mai-Juin, 2000. Disponível em: <https://www.persee.fr/doc/homig_1142852x_2000_num_1225_1_3506>. Acesso em: 12 dez. 2019.

9. LESSAULT, D.; FLAHAUX, M.L. Regards statistiques sur l'histoire de l'émigration internationale au Sénégal. Revue Européenne des Migrations Internationales, Marseille, v. 29, n. 4, p. 59-88, 2013. Disponível em: <https://doi.org/10.4000/remi.6640>. Acesso em 12 dez. 2019.

10. LiBerato FILHO, G. F. P., SANTOS, Z. M. S. A., CALDAS, J. M. P., JARDIM, M. H. A. G., CAPELO, M. R. T. F., \& SANTOS, P. D. S. Estudantes africanas imigrantes no Ceará: análise do processo adaptativo. Revista Psicologia, Diversidade e Saúde, Salvador, v. 8, n.2, p. 240-248, 2019. Disponível em: <https://www5.bahiana.edu.br/index.php/psicologia/article/view/2402>. Acesso em: 12 dez. 2019.

11. MINAYO, Maria Cecília de Souza. O desafio do conhecimento: pesquisa qualitativa em saúde. 11 ed. São Paulo: Hucitec, 2008.

ORTNER, S. B. Subjetividade e crítica cultural. Horiz. antropol., Porto Alegre, v. 13, n. 28, p. 375405, Dez. 2007. Disponível em: <https://doi.org/10.1590/S0104-71832007000200015>. Acesso em: 12 dez. 2019.

13. ROCHA, C. M. F.; DARSIE, C.; GAMA, A.; DIAS, S. Migração Internacional e Vulnerabilidade em Saúde: Tópicos sobre as Políticas de Saúde e de Saúde Sexual e Reprodutiva em Portugal. Hygeia - Revista Brasileira de Geografia Médica e da Saúde, v. 8, n. 15, 21 dez. 2012. Disponível em: <http://www.seer.ufu.br/index.php/hygeia/article/view/17881>. Acesso em: 13 dez. 2019.

14. RODRIGUES, R. e DIAS, S. Encontro com a diferença: a perspectiva dos profissionais de saúde no contexto da prestação de cuidados aos imigrantes. Forum Sociológico, v. 22, 2012. Disponível em: <https://journals.openedition.org/sociologico/583>. Acesso em: 13 dez. 2019.

SANTINHO, C. A importância da competência cultural no atendimento de saúde a refugiados e requerentes de asilo. Forum Sociológico, v. 22, 2012. Disponível em: <https://doi.org/10.4000/sociologico.594>. Acesso em: 10 dez. 2019.

16. TARDÁGUILA, C. e MARÉS, C. Mitos e verdades sobre novo surto de sarampo, doença altamente contagiosa. Folha de São Paulo, 4 de julho de 2018. Disponível em: <https://piaui.folha.uol.com.br/lupa/2018/07/04/mitos-e-verdades-sarampo/>. Acesso em: 20 nov. 2019. 
17. TOPA, J.; NEVES, S. e NOGUEIRA, C. Imigração e saúde: a (in)acessibilidade das mulheres imigrantes aos cuidados. Saúde Soc., São Paulo, v.22, n. 2, p.328-341, 2013. Disponível em: <https://doi.org/10.1590/S0104-12902013000200006>. Acesso em: 20 nov. 2019.

\section{Ivana dos Santos Teixeira}

Doutora em Antropologia Social. Pós-Doutorado junto à Universidade Federal do Rio Grande do Sul.

\section{Rosane Machado Rollo}

Mestre em Saúde Coletiva (UFRGS) e Mestranda em Educação (UFRGS).

\section{Cristianne Maria Famer Rocha}

Doutora em Educação, Professora Associada da Escola de Enfermagem/UFRGS, Departamento de Saúde Coletiva.

\section{Como citar este documento:}

TEIXEIRA, Ivana dos Santos; ROLLO, Rosane Machado; ROCHA, Cristianne Maria Famer. UM DIÁLOGO PLURICULTURAL SOBRE O ACESSO À SAÚDE COM MULHERES IMIGRANTES. Reflexão e Ação, Santa Cruz do Sul, v. 29, n. 1, p. 84-97, jan. 2021. ISSN 1982-9949. Acesso em: doi: http://dx.doi.org/10.17058/rea.v29i1.14815 